\title{
Grain Boundary Engineering of 10\% Cr Ferritic-Martensitic Steel SUH3
}

\author{
Kyosuke HIRAYAMA, ${ }^{1)}$ Yonosuke YOSHII, ${ }^{2)}$ Yasuhiro MORIZONO, ${ }^{2)}$ Sadahiro TSUREKAWA ${ }^{2 \mid *}$ and \\ Yasuyosi HIDAKA ${ }^{3)}$
}

1) Formerly Department of Materials Science and Engineering, Graduate School of Science and Technology, Kumamoto University. Now at Department of Mechanical Engineering, Kyushu University, Fukuoka, 819-0395 Japan.

2) Department of Materials Science and Engineering, Graduate School of Science and Technology, Kumamoto University, Kumamoto, 860-8555 Japan. $\quad 3)$ Nippon Steel \& Sumitomo Metal Corporation Technical Research \& Development Steel Research Laboratories, 1-8 Fuso-cho, Amagasaki, Hyogo, 660-0891 Japan.

(Received on February 9, 2015; accepted on May 13, 2015)

\begin{abstract}
Thermomechanical treatments for manipulating grain boundary microstructure in $10 \mathrm{wt} \% \mathrm{Cr}$ ferriticmartensitic steel SUH3 have been studied. Material with a high fraction of coincidence site lattice (CSL) boundaries was successfully produced and subjected to steam oxidation tests to demonstrate the utility of grain boundary engineering. Introducing a high fraction of twin boundaries in austenite resulted in a significant increase in the number of CSL boundaries along the prior austenite grain boundaries in martensite. In addition, grain boundary engineering introduced a high density of subblock structures in martensite, which resulted in a homogeneous distribution of fine precipitates in tempered martensite. Steam oxidation tests demonstrated that grain boundary engineering for SUH3 steel can achieve enhanced oxidation resistance.
\end{abstract}

KEY WORDS: grain boundary engineering; ferritic-martensite steel; steam oxidation test.

\section{Introduction}

More than $30 \%$ of the total $\mathrm{CO}_{2}$ gas is emitted from thermal power plants in the world. In the face of worldwide environmental challenges such as climate change, it is critical to increase the conversion efficiency of thermal power plants to decrease gas emissions. The latest generation of thermal power plants is running with a conversion efficiency of $43 \%$ at operating temperature of $893 \mathrm{~K}$. It is essential to increase operating temperatures to further reduce $\mathrm{CO}_{2}$ gas emission from the thermal power plants. Ferritic steels with a tempered martensitic microstructure are usually used as heat-resistant materials for boilers, turbines and pipework in thermal power plants, which operate between $723 \mathrm{~K}$ and $893 \mathrm{~K}$ under steam oxidation conditions. Extensive studies have reported that prior austenite grain boundaries (PAGB) behave as preferential sites for creep fracture when the prior austenite grains are coarse. ${ }^{1,2)}$ In addition, the PAGB act as preferential sites for the precipitation of coarse carbides and void nucleation, and for recovery of high-density dislocations that promotes the formation of coarse subgrains near PAGB. ${ }^{3-7)}$ Thus, if we can control the properties of PAGB and reduce the frequency of these phenomena, we can expect superior heat-resistant ferritic steels that are able to withstand higher operating temperature to increase thermal efficiency.
Grain boundary engineering, which can be used to enhance material properties, ${ }^{8,9)}$ is not commonly applied to materials with body-centered cubic structures. This is likely because of the difficulty of introducing coincidence site lattice (CSL) boundaries, particularly $\Sigma 3$ twins and their related CSL boundaries, such as $\Sigma 9$, into materials with a high stacking fault energy. Gupta et al. ${ }^{10)}$ applied a thermomechanical processing route consisting of cold-rolling with several reduction ratios and subsequent annealing at 1323 $\mathrm{K}$ for $3.6 \mathrm{ks}$ to manipulate the grain boundary character distribution in a $9 \mathrm{wt} \% \mathrm{Cr}$ steel T91, and found that this processing route could increase the fraction of CSL boundaries. Subsequently, Was et al. ${ }^{11)}$ and Gupta and Was ${ }^{12)}$ demonstrated that the creep resistance of the ferritic steel T91 was improved by increasing the density of subgrain boundaries. Recently, one of the authors of current study proposed a new processing route for controlling grain boundary microstructure in $12 \mathrm{wt} \% \mathrm{Cr}$ ferritic steel with a combination of thermomechanical treatments, including hot-rolling and subsequent annealing, and found that the fraction of CSL boundaries along PAGB in martensite increased with the increasing fraction of prior austenite CSL boundaries. ${ }^{13)}$ The microstructure resulting from this processing for a $10 \mathrm{wt} \%$ $\mathrm{Cr}$ ferritic steel SUH3 is the topic of the present study, with the aim of confirming the effect of grain boundary control on the steam oxidation resistance.

\footnotetext{
* Corresponding author: E-mail: turekawa@kumamoto-u.ac.jp DOI: http://dx.doi.org/10.2355/isijinternational.ISIJINT-2015-057
} 


\section{Experimental Procedures}

The material used in this study was a $10 \mathrm{wt} \% \mathrm{Cr}$ ferritic steel SUH3 with chemical composition $10.13 \mathrm{Cr}-0.41 \mathrm{C}$ 1.88Si-0.25Mn-0.28P-0.09S-0.21Ni-0.71Mo-0.10Cu (wt $\%$ ). This as-received material was austenized at $1303 \mathrm{~K}$ for 2.7 $\mathrm{ks}$ and oil quenched, and then tempered at $1003 \mathrm{~K}$ for 3.6 ks. To introduce a high fraction of annealing twins in the austenite phase, the as-received samples were austenized at $1373 \mathrm{~K}$ for $2.7 \mathrm{ks}$, and then hot-rolled to reduction ratios from 5 to $30 \%$. These hot-rolled samples were subsequently annealed at $1373 \mathrm{~K}$ for $2.7 \mathrm{ks}$ and then air-cooled. Thereafter, the samples were subjected to tempering at $1003 \mathrm{~K}$ for $3.6 \mathrm{ks}$. These samples are hereafter referred as to grain boundary engineered samples.

Quantitative evaluation of grain boundary microstructure was performed using scanning electron microscopy (SEM) and electron backscatter diffraction (EBSD) using a Hitachi S-4200 FE-SEM equipped with the TSL's OIM system, operating at accelerating voltage of $20 \mathrm{kV}$, beam current of $10 \mu \mathrm{A}$, and a step size of $0.25-0.30 \mu \mathrm{m}$. For EBSD observation, samples were electro-polished at a voltage of $10 \mathrm{~V}$ and a current density of $0.2 \times 10^{-2} \mathrm{~A} / \mathrm{mm}^{2}$, at $277 \mathrm{~K}$ using a solution of acetic acid 0.77: perchloric acid 0.23. The presence of PAGB and twin boundaries in the austenite phase was crystallographically determined using SEM/ EBSD analysis, assuming the Kurdjumov-Saches orientation. The details of this procedure have been outlined in a previous publication. ${ }^{13)}$ In addition, SEM and transmission electron microscopy (TEM) were used to observe the morphology and distributions of $\mathrm{M}_{23} \mathrm{C}_{6}$ carbides in the tempered conventionally processed and grain boundary engineered samples. TEM observations were conducted using a JEOL JEM-2000FX operating at $200 \mathrm{kV}$. The thin foils suitable for TEM observations were prepared by a twin-jet electropolishing in the mixture of acetic acid 0.90: perchloric acid 0.10: methanol 0.10 , working at $278 \mathrm{~K}, 20 \mathrm{~V}$, and $0.05 \mathrm{~A} / \mathrm{mm}^{2}$.

Steam oxidation tests were performed at temperatures ranging from 873 to $1073 \mathrm{~K}$ under $100 \% \mathrm{H}_{2} \mathrm{O}$, and the resultant samples were subjected to SEM observation and electron probe microanalysis (EPMA). The samples for the steam oxidation tests were mechanically polished with \#600 $\mathrm{SiC}$ waterproof paper and then chemically etched with $10 \%$ oxalic acid to remove surface strain. EPMA was performed using a Shimadzu EPMA-1720H operating at an accelerating voltage of $15 \mathrm{kV}$.

\section{Results and Discussion}

\subsection{Microstructure Characterization}

Figures 1(a) and 1(b) show SEM micrographs of the cross-section and surface, respectively, of as-received material. These micrographs show a typical lath martensitic microstructure with several PAGB visible and formation of many precipitates on the grain boundaries. Figure 2 shows SEM micrographs of the samples that were hot deformed at $1373 \mathrm{~K}$ using reduction ratios (a) $0 \%$, (b) $5 \%$, (c) $10 \%$, and (d) $20 \%$, and subsequently annealed at $1373 \mathrm{~K}$ for 2.7 ks. These micrographs also show a typical lath martensitic microstructure with several PAGB. The prior austenite grains increase with increasing reduction ratio but decrease at a $20 \%$ reduction ratio. Figure 3 shows the change in the average prior austenite grain size with the reduction ratio. For comparison, the prior austenite grain size in as-received
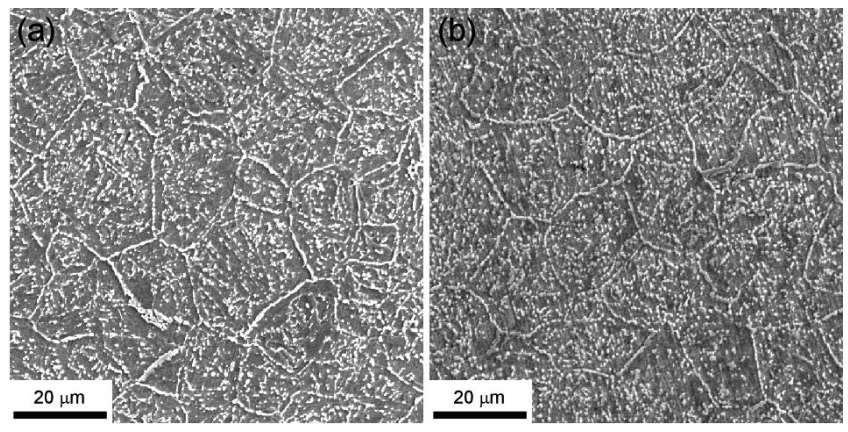

Fig. 1. SEM micrographs of the (a) cross-section and (b) surface of as-received material.
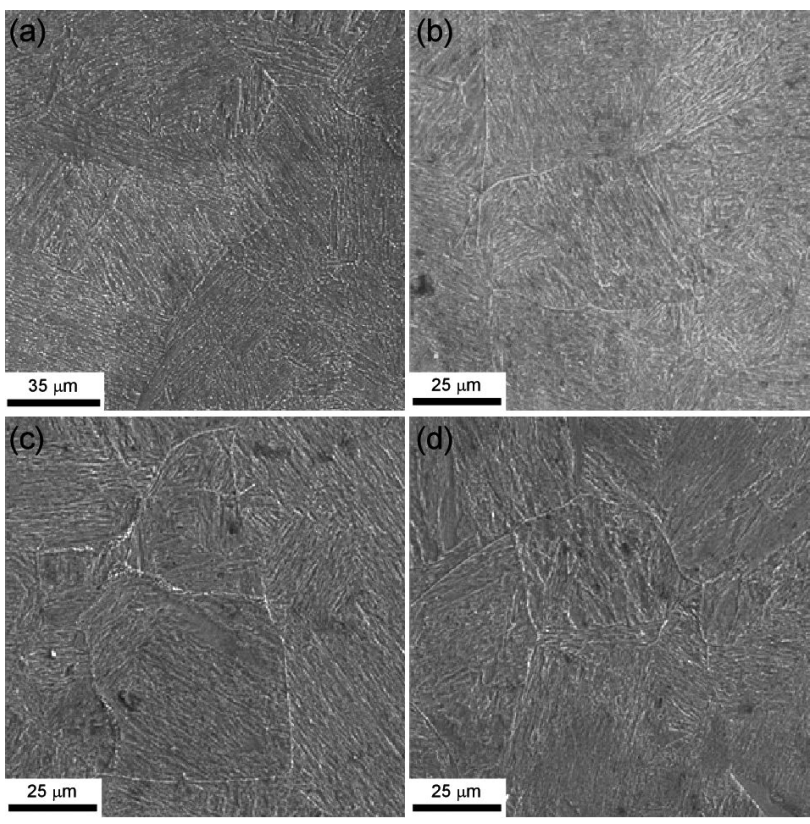

Fig. 2. SEM micrographs of the samples that were hot deformed at $1373 \mathrm{~K}$ with reduction ratios of (a) $0 \%$, (b) $5 \%$, (c) $10 \%$, and (d) $20 \%$, and subsequently annealed at $1373 \mathrm{~K}$ for $2.7 \mathrm{ks}$.

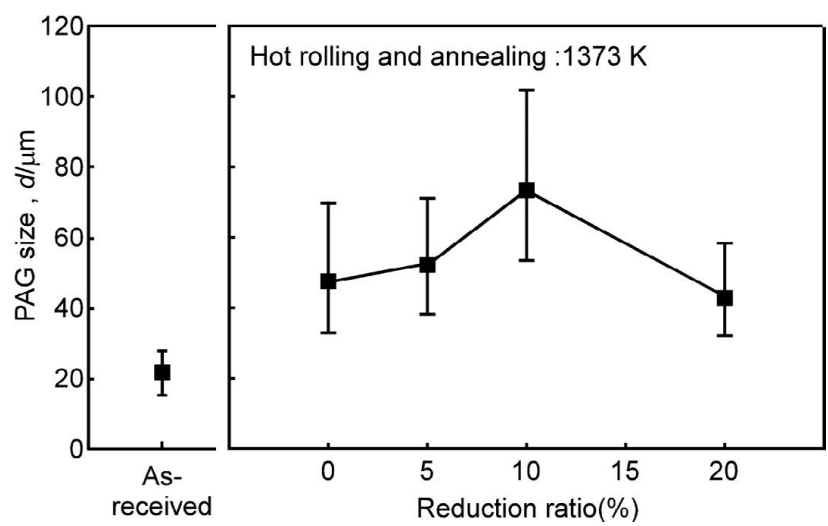

Fig. 3. Change in average prior austenite grain size with the reduction ratio. 
materials is also shown in Fig. 3. The average size of prior austenite grains increased with increasing reduction ratio up to $10 \%$, then decreased at the reduction ratio of $20 \%$. The strain introduced by hot-rolling may have promoted grain boundary migration in material with a reduction ratio of less than $10 \%$, and then induced recrystallization when the reduction ratio reached $20 \%$. In a previous experience, we found that the grain boundary migration is often accompanied by formation of annealing twins in materials with low stacking fault energy. ${ }^{13)}$ Therefore, we can expect that a high fraction of twin boundaries, which correspond to the $\{111\}$ $\Sigma 3$ grain boundary, would be introduced into the austenite phase for the sample rolled at a $10 \%$ reduction ratio.

Figures 4 and $\mathbf{5}$ present the EBSD micrographs for the as-received samples and for the sample hot-rolled at $1373 \mathrm{~K}$ with a $10 \%$ reduction ratio and subsequently annealed at
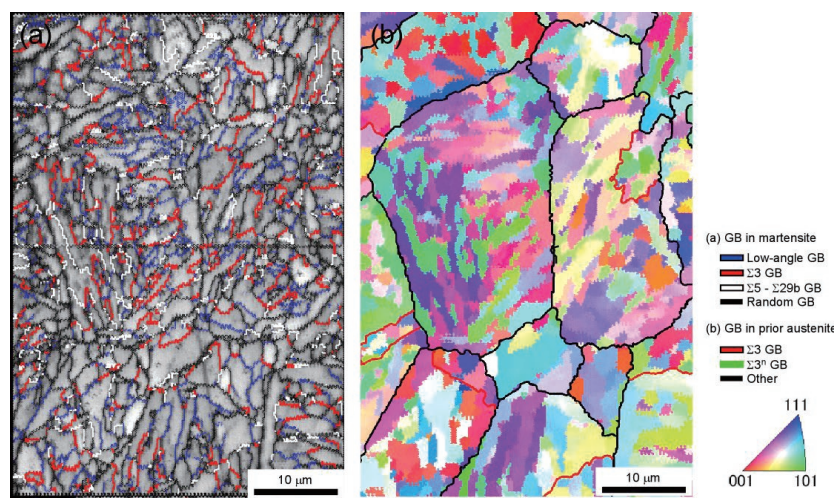

Fig. 4. EBSD micrographs from the as-received samples. (a) IQ maps showing the character of individual grain boundaries in the martensite phase. (b) IPF maps showing the PAGB, twin boundaries, and $\Sigma 3^{\mathrm{n}}$ boundaries in the austenite phase. In (a), low angle, $\Sigma 3, \Sigma 5-\Sigma 29 b$, and random grain boundaries are inidcated with blue, red, white, and black lines, respectively. In (b), PAGB, prior austenite $\Sigma 3$ boundaries (twin boundaries) and prior austenite $\Sigma 3^{n}$ boundaries are indicated with black, red, and green lines, respectively.

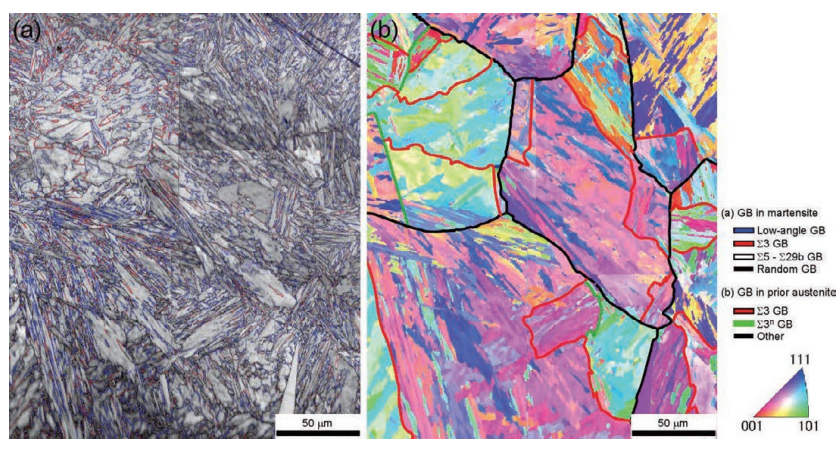

Fig. 5. EBSD micrographs from the sample that was hot-rolled at $1373 \mathrm{~K}$ with a $10 \%$ reduction ratio and subsequently austenized at $1373 \mathrm{~K}$ for $2.7 \mathrm{ks}$. (a) IQ maps showing the character of individual grain boundaries in the martensite phase. (b) IPF maps showing the PAGB, twin boundaries, and $\Sigma 3^{\mathrm{n}}$ boundaries in the austenite phase. In (a), low angle, $\Sigma 3, \Sigma 5-\Sigma 29$ b, and random grain boundaries are indicated with blue, red, white, and black lines, respectively. In (b), PAGB, prior austenite $\Sigma 3$ boundaries (twin boundaries) and prior austenite $\Sigma 3^{\mathrm{n}}$ boundaries are indicated with black, red and green lines, respectively.
$1373 \mathrm{~K}$ for $2.7 \mathrm{ks}$, respectively. Figures 4(a) and 5(a) display the image quality (IQ) maps showing the character of individual grain boundaries in the martensite phase, while Figs. 4(b) and 5(b) present the inverse pole figure (IPF) maps showing the PAGB, twin boundaries, and $\Sigma 3^{\mathrm{n}}$ boundaries in the austenite phase. In Figs. 4(a) and 5(a), low angle, $\Sigma 3, \Sigma 5-\Sigma 29$ b, and random grain boundaries are displayed by blue, red, white, and black lines, respectively. In Figs. 4(b) and 5(b), PAGB, prior austenite $\Sigma 3$ boundaries (twin boundaries), and prior austenite $\Sigma 3^{\mathrm{n}}$ boundaries are shown by black, red and green lines, respectively. Comparing these maps, we find that the number of low-angle grain boundaries, which likely correspond to subblock boundaries in martensite, is significantly increased by hot-rolling and subsequent annealing. There is also an increase in prior austenite grain size following hot-rolling and annealing. Figure 6 shows the length fraction of low-angle, CSL, and random grain boundaries in the as-received samples and in the sample hot-rolled at $1373 \mathrm{~K}$ with a $10 \%$ reduction ratio and subsequently annealed at $1373 \mathrm{~K}$ for $2.7 \mathrm{ks}$. In the as-received samples, the fractions of random grain boundaries, low-angle grain boundaries, and CSL boundaries were found to be $0.50,0.22$, and 0.28 , respectively. The fraction of low-angle grain boundaries in the sample hot-rolled at $1373 \mathrm{~K}$ with $10 \%$ reduction ratio $(0.50)$ was high in comparison with that of the as-received samples. Conversely, the fraction of random grain boundaries decreased following hot-rolling and annealing. In addition, the $\Sigma 3$ grain boundaries (twin boundaries) in the austenite phase appear to increase following this thermomechanical treatment. Annealing twin boundaries are typically very straight-sided. However, twin boundaries identified often have an irregularshaped interface. This is because, at coherent twin boundaries in austenite, the martensite variants formed are often the variants "sheared" between the twin-related austenite grain and the parent austenite grain, giving a continuous packet across the prior austenite twin boundary. Thus, it is difficult to determine precisely the position of the twin boundary, and experimentally identified twin boundaries can have an irregular-shaped interface.

Figure 7 shows the relationship between the fraction of the prior $\Sigma 3^{\mathrm{n}}$ grain boundaries and the reduction ratio. The

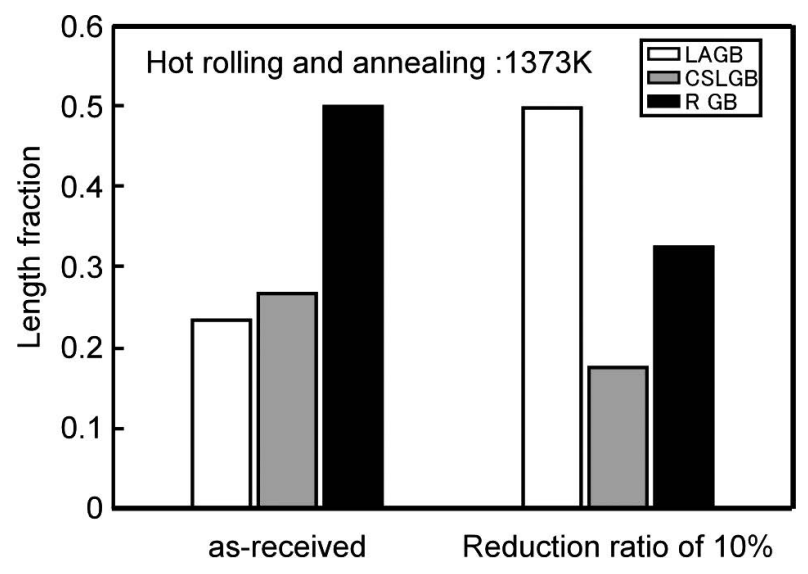

Fig. 6. The length fraction of low-angle, CSL, and random grain boundaries in the as-received samples and in the sample hot-rolled at $1373 \mathrm{~K}$ with a $10 \%$ reduction ratio. 
fraction of twin-related boundaries in prior austenite $f_{\left(\Sigma 3^{n}\right)}^{(\gamma)}$ is given by

$$
f_{\left(\Sigma 3^{n}\right)}^{(\gamma)}=\frac{L_{\left(\Sigma 3^{n}\right)}^{(\gamma)}}{L_{(\text {total })}^{(\gamma)}},
$$

where $L_{\left(\Sigma 3^{n}\right)}^{(\gamma)}$ is the total length of $\Sigma 3^{\mathrm{n}}$ grain boundaries in austenite and $L_{\text {(total })}^{(\gamma)}$ is the total length of all grain boundaries in prior austenite. Changes to the fraction of $\Sigma 3^{\mathrm{n}}$ grain boundaries in austenite with the reduction ratio follow a similar trend to that of prior austenite grain size. The fraction of $\Sigma 3^{\mathrm{n}}$ grain boundaries increased with increasing reduction ratio and showed the maximum value of 0.7 at a $10 \%$ reduction ratio. This fraction decreased at a $20 \%$ reduction ratio. This suggests that grain boundary migration may be accompanied by twin formation. Figure 8 shows the relationship between the fraction of CSL boundaries along the PAGB in martensite and the reduction ratio. The fraction increased up to 0.33 at a $10 \%$ reduction ratio. These results indicate that the $10 \%$ reduction ratio is the optimal condition for introducing a high fraction of CSL grain boundaries along PAGB in martensite. Hereafter, the sample thermomechanically treated with this reduction ratio is described as grain boundary-engineered (GBEed) mate-

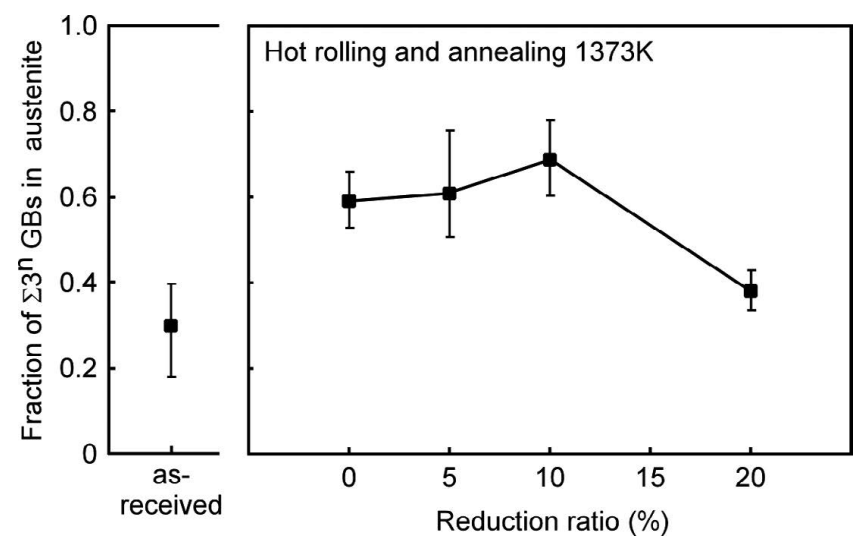

Fig. 7. The relationship between the fraction of the prior $\Sigma 3^{\mathrm{n}}$ grain boundaries and the reduction ratio of the sample hotrolled to reduction ratios from 0 to $20 \%$ at $1373 \mathrm{~K}$.

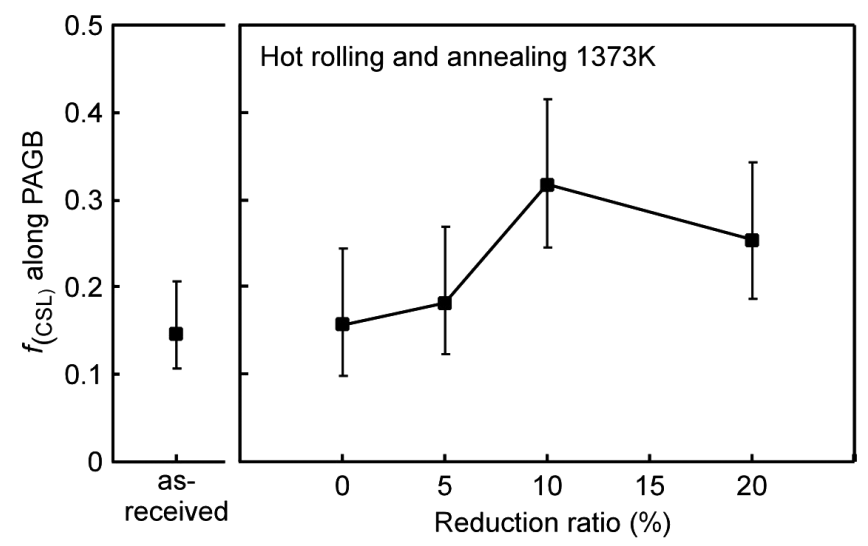

Fig. 8. Relationship between the fraction of CSL boundaries along the PAGB in martensite and the reduction ratio of the sample hot-rolled to reduction ratios from 0 to $20 \%$ at $1373 \mathrm{~K}$. rial. Figure 9 shows the relationship between the fraction of $\Sigma 3^{\mathrm{n}}$ grain boundaries in austenite and the fraction of CSL boundaries along the PAGB in martensite. For comparison, data obtained from $12 \mathrm{wt} \% \mathrm{Cr}$ steel ${ }^{13)}$ is also shown in Fig. 9. As expected, the fraction of CSL boundaries along the PAGB increases monotonously with the increasing fraction of $\Sigma 3^{\mathrm{n}}$ grain boundaries in austenite, irrespective of the grade of steels.

\subsection{Carbide Particles}

SEM micrographs presented in Figs. 10(a) and 10(b) show the distribution of precipitates in as-received and GBEed material tempered at $1003 \mathrm{~K}$ for $3.6 \mathrm{ks}$, respectively. We confirmed that these precipitates were $\mathrm{Cr}_{23} \mathrm{C}_{6}$ carbide from the selected-area electron diffraction pattern as shown in Fig. 11. Grain boundary engineering of SUH3 steel can significantly enhance the fraction of subblock boundaries, which act as preferential nucleation sites of $\mathrm{Cr}_{23} \mathrm{C}_{6}$ carbides, and lead to finely dispersed precipitates. Furthermore, a high fraction of CSL boundaries along PAGB is responsible for preventing precipitates on these boundaries from coarsening, as the diffusivity of CSL boundaries is generally lower than that of random boundaries.

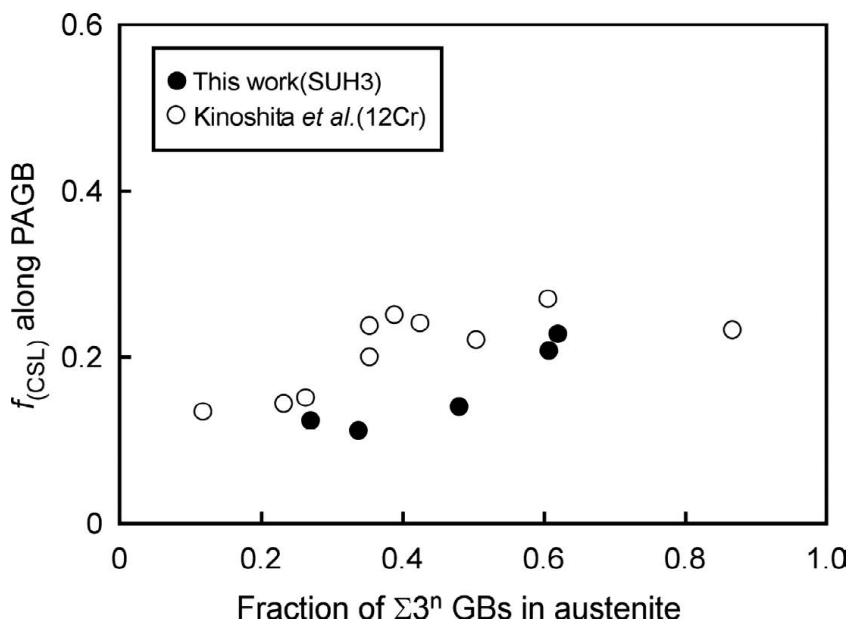

Fig. 9. Relationship between the fraction of $\Sigma 3^{\mathrm{n}}$ grain boundaries in austenite and the fraction of CSL boundaries on PAGB. For comparison, the results obtained from $12 \mathrm{wt} \% \mathrm{Cr}$ steel $^{13)}$ are shown in this figure. Open circles indicate SUH3 steel and filled triangles indicate $12 \mathrm{wt} \% \mathrm{Cr}$ steel.

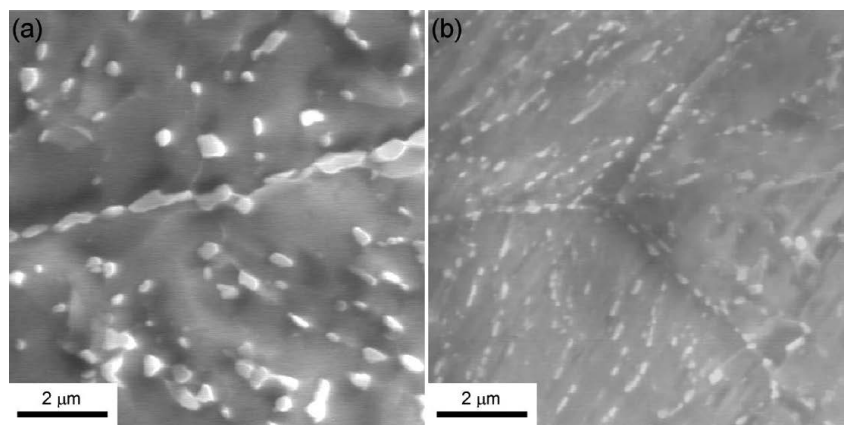

Fig. 10. The SEM micrographs of the morphology of precipitation particles in (a) as-received material and (b) GBEed material. 
Figure 12 presents the size distribution of precipitates on the PAGB (Figs. 12(a) and 12(b)) and in the grain interior (Figs. 12(c) and 12(d)). These distributions in Figs. 12(a) and 12(c) were obtained from the as-received sample and those in Figs. 12(b) and 12(d) were obtained from the GBEed material. The average sizes of precipitates on the PAGB and in the grain interior were $441 \mathrm{~nm}$ and $324 \mathrm{~nm}$, respectively, in the as-received sample, and $163 \mathrm{~nm}$ and $114 \mathrm{~nm}$, respectively, in the GBEed material. In addition,

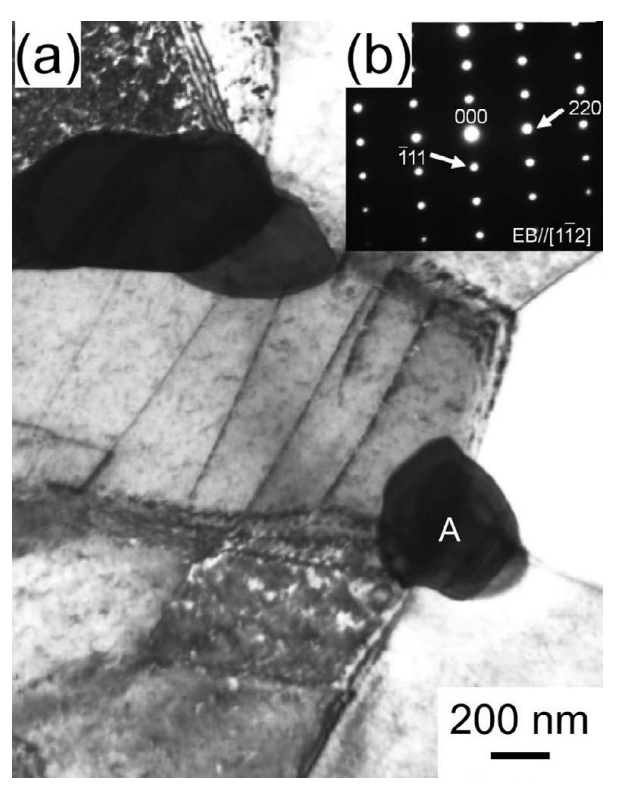

Fig. 11. A TEM bright-field image of the as-received sample and the selected-area diffraction pattern obtained from the area marked with A in the TEM image. the number of precipitates per unit of area was estimated to be $1.10 / \mu \mathrm{m}^{2}$ in the as-received material and $5.35 / \mu \mathrm{m}^{2}$ in the GBEed material. This indicates that the precipitates were dispersed more densely in the GBEed material than in the as-received one. This result suggests that grain boundary engineering of SUH3 steel could achieve enhanced high-temperature strength. Experimental measurement of the high-temperature strength is necessary to quantify any improvement made by grain boundary engineering.

\subsection{Steam Oxidation Tests}

High-temperature steam oxidation tests were carried out from $873 \mathrm{~K}$ to $1073 \mathrm{~K}$ for the GBEed and the as-received materials. Figure 13 presents SEM micrographs that show the formation of oxide scales at the surfaces of the (a, $b$, c) as-received and (d, e, f) GBEed materials after the steam oxidation tests at different temperatures for $86.4 \mathrm{ks}$. These micrographs reveal that two distinct oxide scales were formed, that is, an outer scale and an inner scale, for both materials. Previous studies ${ }^{14-16)}$ suggest that the outer and inner scales should comprise $\mathrm{Fe}_{2} \mathrm{O}_{3}+\mathrm{Fe}_{3} \mathrm{O}_{4}$ and $\mathrm{FeCr}_{2} \mathrm{O}_{4}+\mathrm{Fe}_{3} \mathrm{O}_{4}$, respectively. One interesting observation from the SEM micrographs is that the oxide scales in the GBEed material is thinner than the as-received material, which suggests that grain boundary engineering is useful for enhancing the steam oxidation resistance. Figures 14(a) and 14(b) shows changes in the average thickness of the outer and inner oxide scales, respectively, with temperature. Because there was a large variation of the thickness of oxide scales formed in the GBEed material, whereas the thickness of the oxide scales in the as-received materials was approximately homogeneous, the thickness of the oxide scales in the GBEed materials was distinctively evaluated at the
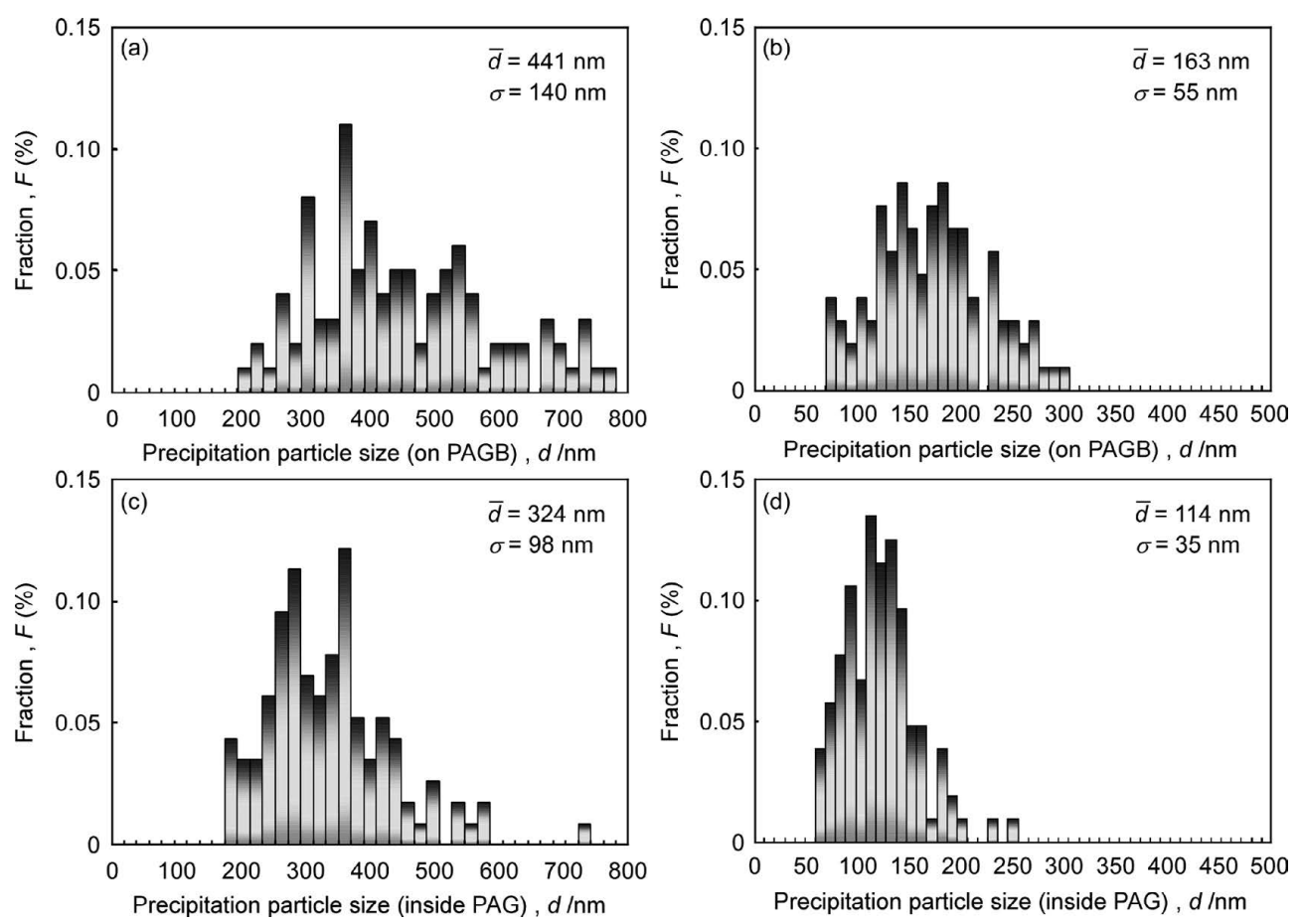

Fig. 12. Histograms of precipitate size on PAGB (a) (b) and in the grain interior (c) (d). These histograms in Figs. 12(a) and 12(c) were obtained from the as-received sample and those in Figs. 12(b) and 12(d) were obtained from the GBEed material. 

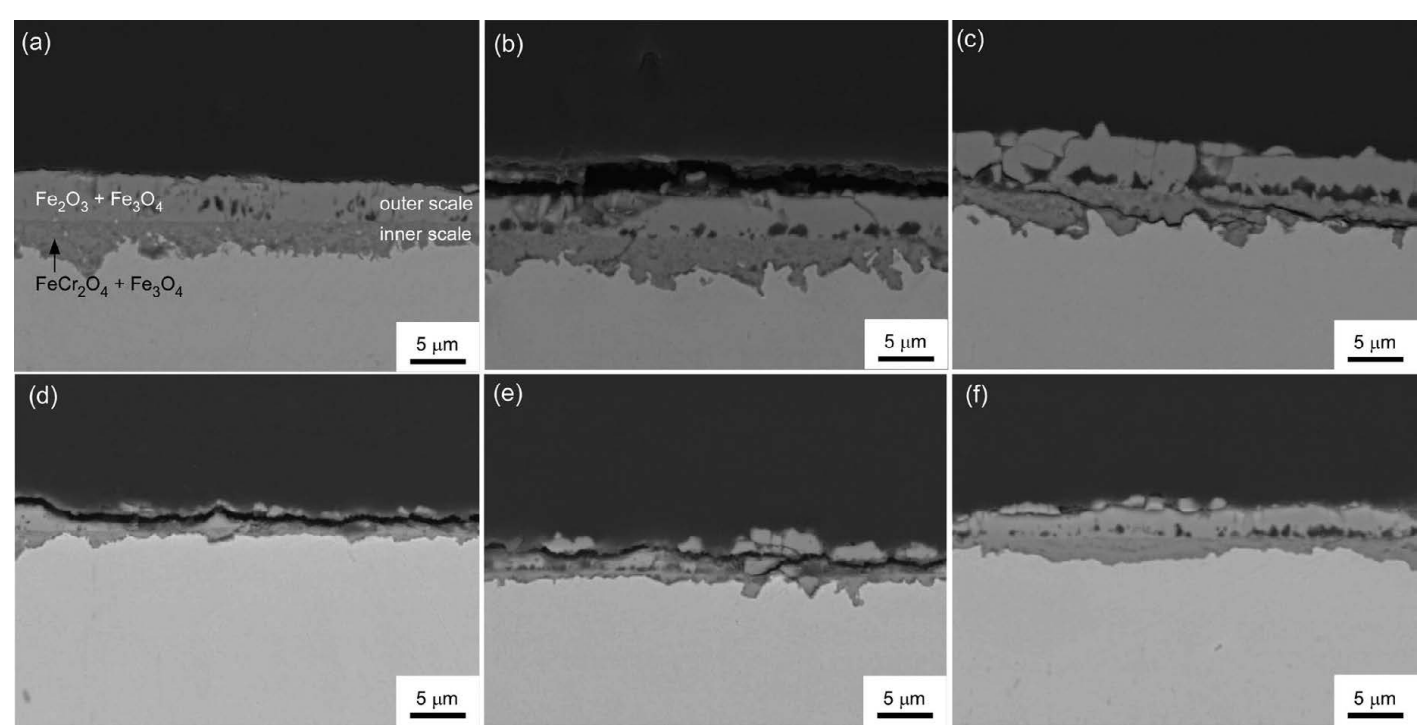

Fig. 13. SEM micrographs showing formation of oxide scales at the surfaces of the (a, b, c) as-received and (d, e, f) GBEed materials after the steam oxidation tests at temperatures of (a) and (d) $873 \mathrm{~K}$, (b) and (e) $973 \mathrm{~K}$, and (c) and (f) $1073 \mathrm{~K}$ for $86.4 \mathrm{ks}$.
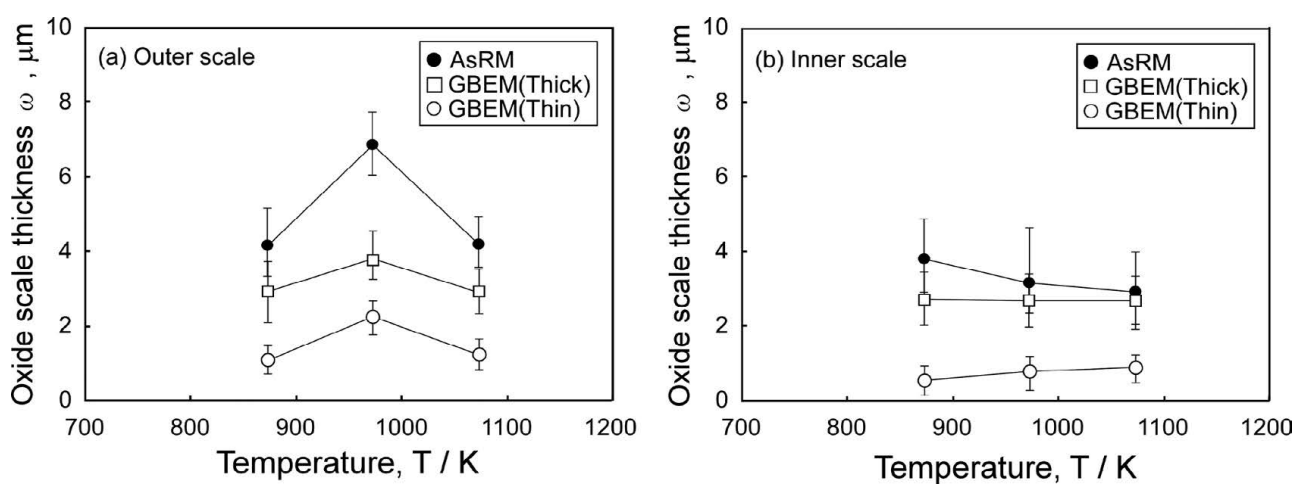

Fig. 14. The (a) outer and (b) inner oxide scale thickness of SUH3 steel after steam oxidation tests. Filled circles indicate as-received materials, open squares and open circles indicate the thickness of thick and thin oxide scale, respectively, in GBEed materials.

areas with thin and thick oxide scales. The thickness of the inner oxide scale in the as-received material decreased with increasing temperature, whereas the inner oxide scale thickness in the GBEed material slightly increased with increasing temperature. Thickness of the outer scales increased up to $973 \mathrm{~K}$, then decreased at $1073 \mathrm{~K}$ in both as-received and GBEed materials. Formation of outer and inner oxide scales is governed by outward diffusion of Fe ions and by inward diffusion of $\mathrm{O}$ ions, respectively. The diffusivity of $\mathrm{O}$ ions in $\mathrm{Fe}_{3} \mathrm{O}_{4}$ is reported to be much lower than that of $\mathrm{Fe}$ ions, ${ }^{17)}$ so that the thickness of the inner oxide scale may decrease as the thickness of the outer oxide scale increases at temperatures between $873 \mathrm{~K}$ and $973 \mathrm{~K}$. However, the thickness of both the outer and inner oxide scales decreased at 1073 $\mathrm{K}$ compared with the thicknesses at $973 \mathrm{~K}$. This could be attributed to quick formation of a Cr- and Si-enriched layer, which would act as barrier for diffusion of $\mathrm{Fe}$ and $\mathrm{O}$ ions as described below.

Results of chemical analysis of the oxide scales formed at $973 \mathrm{~K}$ using the EPMA is shown in Fig. 15(a) as-received material and 15(b) GBEed material. The EPMA chemical maps reveal that the outer and inner oxide scales are likely composed of $\mathrm{Fe}_{3} \mathrm{O}_{4}$ and $(\mathrm{Fe}, \mathrm{Cr})_{3} \mathrm{O}_{4}$, respectively, which is consistent with previous reports. ${ }^{14-16)}$ Moreover, $\mathrm{Cr}$ and $\mathrm{Si}$ enrichment is observed at the interface between the inner scale and the base material in the both samples. Formation of a Cr- and Si-enriched layer would cause a decrease in the oxidation rate because such a layer would act as a barrier for the outward diffusion of Fe ions and the inward diffusion of $\mathrm{O}$ ions. The enrichment of $\mathrm{Cr}$ and $\mathrm{Si}$ at the interface should occur more readily with increasing temperature. This could explain why the thickness of the outer oxide scale formed at $1073 \mathrm{~K}$ was less than the thickness at $973 \mathrm{~K}$. The enhanced oxidation resistance observed in the GBEed material could be attributed to the increase in the fraction of subblock boundaries in martensite, as well as the increase in the fraction of CSL boundaries along PAGB. The subblock boundaries can act as short-circuit diffusion paths for $\mathrm{Cr}$ and $\mathrm{Si}$ atoms towards the surface. Thus, the $\mathrm{Cr}$ - and $\mathrm{Si}$-enriched layer at the scale/base material interface would form more readily in the GBEed material than in the as-received material. Consequently, the GBEed materials may demonstrate enhanced oxidation resistance compared with the conventionally processed as-received material. 
(a)
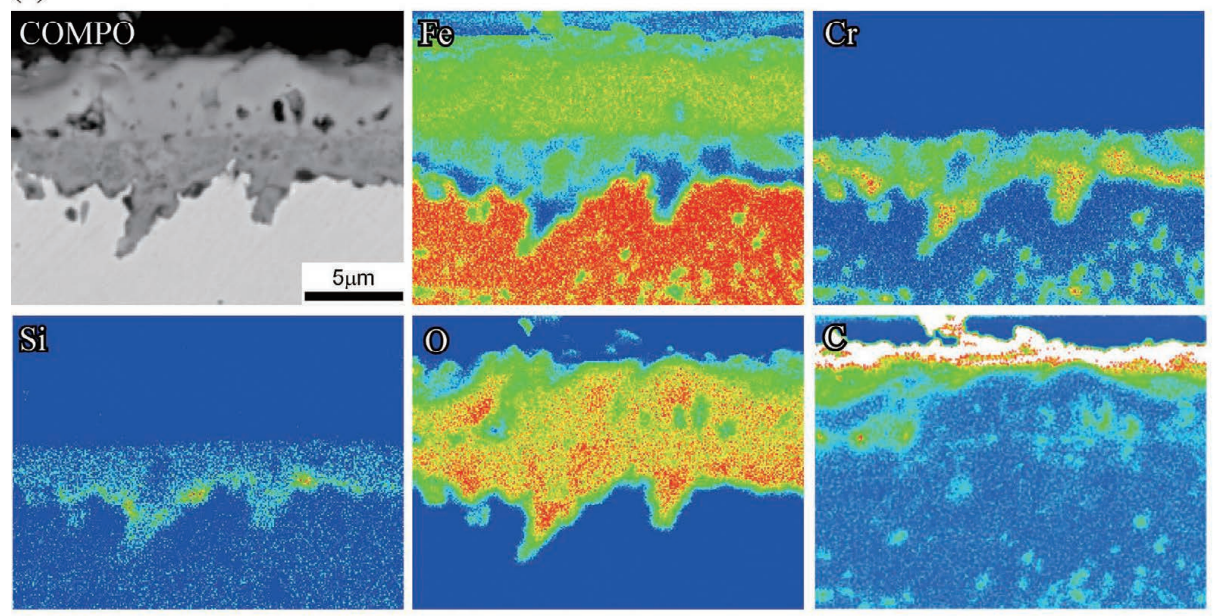

High
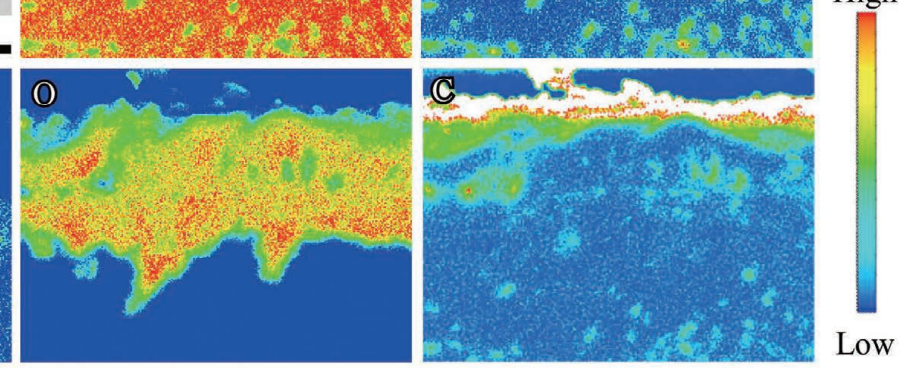

(b)
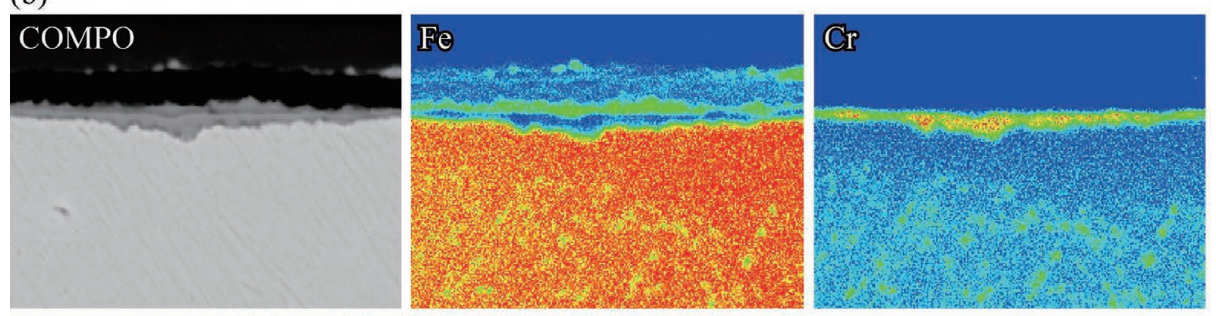

Low
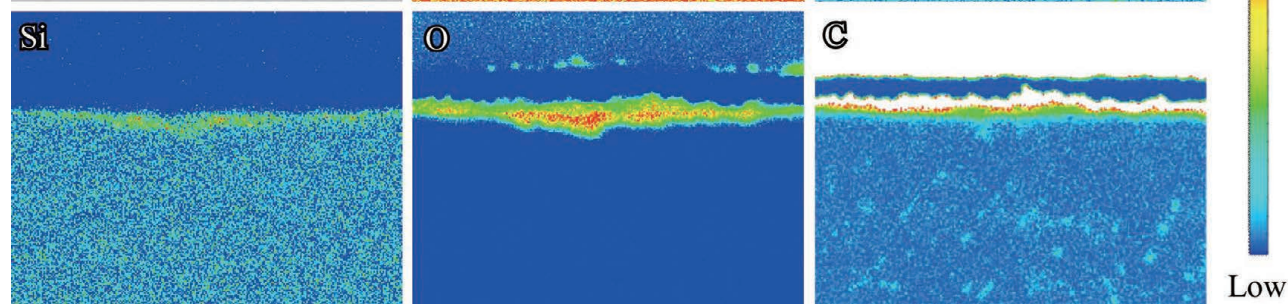

Fig. 15. EPMA mapping data from (a) as-received materials and (b) GBEed materials for the oxide scales formed at $973 \mathrm{~K}$.

\section{Conclusions}

The effect of grain boundary engineering of SUH3 ferritic steel on the steam oxidation resistance was investigated. The primary results obtained are as follows.

(1) The fraction of CSL boundaries along the PAGB in martensite increased with the increasing reduction ratio. A maximum fraction of 0.33 was obtained at a $10 \%$ reduction ratio, suggesting that the $10 \%$ reduction ratio would be the optimal condition for introducing a high fraction of CSL grain boundaries along PAGB in martensite for SUH3 ferritic steel.

(2) The fraction of CSL boundaries along PAGB was found to increase monotonously by increasing the fraction of $\Sigma 3^{\mathrm{n}}$ grain boundaries in austenite, irrespective of the grade of steels.

(3) The precipitates were dispersed more densely in the GBEed material than in the as-received material.

(4) The GBEed material may have achieved enhanced oxidation resistance compared with conventionally processed as-received material.

\section{Acknowledgments}

The authors thank Dr. T. Yamamuro (Kumamoto Univerisity) for his help with the experimental work. This study was supported by the Iron and Steel Institute of Japan
Research Promotion Grant and by the Japan Society for the Promotion of Sciences KAKENHI for Basic Research (A) (Grant No. 24246125). These supports are greatly appreciated.

\section{REFERENCES}

1) S. H. Hong and J. Yu: Scr. Metall., 23 (1989), 1057.

2) K. Kimura, N. Ohi, K. Shimazu, T. Matsuo, R. Tanaka and M. Kikuchi: Scr. Metall., 21 (1987), 19.

3) C. R. Brooks and F. Bogni: Mater. Charact., 38 (1997), 103

4) M. Matsui, M. Tabuchi, T. Watanabe, K. Kubo, J. Kinugawa and F. Abe: ISIJ Int., 41 (2001), S126.

5) F. Abe, T. Horiuchi, M. Taneike and K. Sawada: Mater. Sci. Eng. A, 378 (2004), 299.

6) F. Abe: Sci. Tech. Adv. Mater., 9 (2008), 013002.

7) F. Abe: Mater. Sci. Eng. A, 510-511 (2009), 64.

8) T. Watanabe: Res Mechanica, 11 (1984), 47.

9) T. Watanabe and S. Tsurekawa: Acta Mater., 47 (1999), 4171.

10) G. Gupta, B. Alexandreanu and G. S. Was: Metall. Mater. Trans., 35A (2004), 717.

11) G. S. Was, B. Alexandreanu, P. Andresen and M. Kumar: Mater. Res. Soc. Symp. Proc., Vol. 819, Material Reserch Society, Warrendale, Pennsylvania, (2004), N2.1.1.

12) G. Gupta and G. S. Was: Metall. Mater. Trans., 39A (2007), 150.

13) Y. Kinoshita, V. A. Yardley and S. Tsurekawa: J. Mater. Sci., 46 (2011), 4261.

14) S. Hayashi, M. Fukumoto, S. Maeda and T. Narita: Zairyo-toKankyo, 51 (2002), 115.

15) Y. Yutaka, Y. Yi, T. Kondo, K. Suzuki and K. Kano: Zairyo-toKankyo, 50 (2001), 50.

16) I. G. Wright and R. B. Dooley: Int. Mater. Rev., 55 (2010), 129.

17) M. Backhaus-Ricoult and R. Dieckmann: Ber. Bunsenges. Phys. Chem., 90 (1986), 690. 